\title{
The frequency of blindness and visual impairment in the central-west region of Brazil
}

\author{
A frequência de cegueira e visão subnormal na região Centro-Oeste do Brasil \\ Guilherme B. Ribeiro' (D), Giuliano P. Dobri', Ricardo Y. Abe (D) \\ 1. Hospital Oftalmológico de Brasília, Brasília, DF, Brazil.
}

Dear Editor,

It is estimated that approximately 1.1 million people worldwide experience vision loss primarily because they do not have access to eye care services. Over $90 \%$ of those people live in low- and middle-income countries, $74 \%$ are older than 50 years, and $55 \%$ are women ${ }^{(1)}$. The World Health Organization defines blindness as best-corrected visual acuity (BCVA) of worse than $1.3 \log$ MAR in the better eye and low vision or visual impairment as best-corrected visual acuity of 0.5 to 1.3 $\log M A R$ in the better eye ${ }^{(2)}$.

According to the most recent survey by the Brazilian Geography and Statistic Institute, 3.6\% of the Brazilian population (7.2 million citizens) have blindness or visual impairment ${ }^{(3)}$. Nonetheless, data regarding blindness and low vision frequencies in the central-west region of Brazil are scarce. We therefore investigated the frequency and causes of visual impairment and blindness in a reference visual care foundation in Brasília during the years 2016 to 2018.

A total of 3002 medical records from first appointments in the clinic were analyzed. Of these, 258 cases of blindness and visual impairment were eligible for this study; 101 (39.1\%) of the patients were men, and 157 (60.9\%) were women. The mean age of the patients was $67.77 \pm 16.85$, and their ages ranged from 6 to 98 years. The mean BCVA in the first appointment was 0.97 $\pm 0.38 \log M A R$.
To analyze the causes of visual impairment and blindness, we divided the 258 patients into two groups: 86 patients who had the same BCVA in both eyes and 172 patients who had different BCVAs. The most frequent primary causes in the latter group were cataract (113 cases [65.7\%]), glaucoma (11 cases [6.4\%]), and posterior capsule opacification (10 cases [5.8\%]; Table 1). Of those 172 patients, 97 received ocular treatment after the first clinic appointment. The mean BCVAs before and after treatment were $0.90 \pm 0.33 \log M A R$ and 0.26 $\pm 0.39 \log$ MAR, respectively $(p<0.001, t$ test $)$. After the treatment, 86 patients $(88.7 \%)$ experienced improvement in their vision by $0.5 \operatorname{logMAR}$ or better; of the other 11 patients (11.3\%); however, 7 (7.2\%) experienced no improvement in BCVA after the procedure, and the others experienced worsening of BCVA by more than $0.5 \log M A R$. For all 11, glaucoma was the primary cause of visual impairment.

Among the 86 patients who had the same BCVA in both eyes, the most frequent causes of visual impairment in the right eyes were cataract (64 cases [74.4\%]), glaucoma (5 cases [5.8\%]) and posterior capsule opacification (7 cases [5.8\%]). Among the left eyes, the most frequent causes of visual impairment were cataract (62 cases [72.0\%]), glaucoma (5 cases [5.8\%]), and posterior capsule opacification (5 cases [5.8\%]; Table 2).

Table 1. Most prevalent causes of visual impairment and blindness among 172 patients

\begin{tabular}{lc}
\hline Etiology & $\mathbf{n}$ \\
\hline Cataract & $113(65.7 \%)$ \\
Glaucoma & $11(6.4 \%)$ \\
Posterior capsule opacification & $10(5.8 \%)$ \\
Keratoconus & $8(4.7 \%)$ \\
Diabetic retinopathy & $8(4.7 \%)$ \\
\hline
\end{tabular}


Table 2. Most prevalent causes of visual impairment and blindness in 86 patients with the same best-corrected visual acuity in both eyes

\begin{tabular}{lcc} 
& \multicolumn{2}{c}{$\mathbf{n}$} \\
\cline { 2 - 3 } Etiology & Right eyes & Left eyes \\
\hline Cataract & $64(74.4 .7 \%)$ & $62(72.0 \%)$ \\
Glaucoma & $5(5.8 \%)$ & $5(5.8 .2 \%)$ \\
\hline Posterior capsule opacification & $7(5.8 \%)$ & $5(5.8 .2 \%)$ \\
\hline Keratoconus & $2(2.3 \%)$ & $2(2.3 \%)$ \\
\hline Diabetic retinopathy & $2(2.3 \%)$ & $2(2.3 \%)$ \\
\hline
\end{tabular}

According to our findings, cataract was the leading cause of visual impairment, which corroborates the findings reported in global populations ${ }^{(4)}$. Of our patients, $89 \%$ were older than 50 years, and $57.91 \%$ were women. Similar results were found in the Los Angeles Latino Eye Study, in which $80 \%$ of visually impaired people worldwide were 50 years of age or older. That study also demonstrated that visual impairment increased with age and was more severe in women ${ }^{(5)}$.

Despite being the most prevalente cause of visual impairment, the visual loss from cataract is reversible. The high frequency of irreversible visual impairment and blindness in patients with glaucoma is of great concern. Of the 97 patients who received ocular treatment in our sample, the 7 patients (7.2\%) who did not experience improvement in BCVA after treatment had glaucoma. The Brazilian population is growing in number and is aging; thus the risk of blindness and visual impairment might increase further. Our findings help clarify the frequency of blindness and visual impairment in the central-west region of Brazil and highlight the importance of access to proper eye care in minimizing the risk of blindness and visual impairment.

\section{REFERENCES}

1. Bourne R, Adelson J, Flaxman S, Briant PS, Taylor HR, Casson RJ et al. Trends in prevalence of blindness and distance and near vision impairment over 30 years and contribution to the global burden of disease in 2020. Lancet Glob Health. 2020;9(2):130-43.

2. Couto Junior A, Oliveira LAG. The main causes of blindness and low vision in school for blind. Rev Bras Oftalmol. 2016;75(1):26-9.

3. Instituto Brasileiro de Geografia e Estatística (IBGE). Tabela. Pessoas com Deficiência Visual, Total, Percentual e Coeficiente de Variação por Grupos de Idade e situação do domicílio [Updated, 2013]. Disponível em: https://sidra.ibge.gov.br/Tabela/5753;5753.

4. Flaxman SR, Bourne RRA, Resnikoff S, Ackland P, Braithwaite T, Cicinelli MV, et al. Global causes of blindness and distance vision impairment 1990-2020: a systematic review and meta-analysis. Lancet. Global Health. 2017;5(12):e1221-34.

5. Varma R, Ying-Lai M, Klein R, Azen SP, Los Angeles Latino Eye Study Group. Prevalence and risk indicators of visual impairment and blindness in Latinos: the Los Angeles Latino Eye Study. Ophthalmology. 2004;111(6):1132-40. 